\title{
Mycorrhizal Inoculation Increases Growth and Induces Changes in Specific Polyphenol Levels in Olive Saplings
}

\author{
Nasir S. A. Malik ${ }^{1}$, Alberto Nuñez $^{1} \&$ Lindsay C. McKeever ${ }^{1}$ \\ ${ }^{1}$ USDA-ARS, ERRC, Wyndmoor, PA, USA \\ Correspondence: Nasir S. A. Malik, USDA-ARS, ERRC, 600 E Mermaid Lane, Wyndmoor, PA 19038-8598, \\ USA. Tel: 1-215-233-6690. E-mail: nasir.malik@ars.usda.gov
}

Received: September 20, 2016

Accepted: October 31, 2016

Online Published: January 15, 2017

doi:10.5539/jas.v9n2p1

URL: http://dx.doi.org/10.5539/jas.v9n2p1

\begin{abstract}
This study was conducted to investigate the effect of mycorrhizal symbiosis on the levels of polyphenols in olive saplings. Rooted stem cuttings of olive cultivar, 'Arbequina', were inoculated with AM fungus Rhizophagus intraradices. The inoculated plants showed more robust growth after six months, and after nine months the increase in the mycorrhizal plant's height was $146 \%$, and the increase in number of leaves was $117 \%$ when compared to uninoculated controls. Polyphenols in the methanol extracts of leaves were separated by HPLC and the peaks identified by using commercially available standard compounds and comparing retention time and the mass obtained with the mass spectrometer. Oleuropein, which is a major component of the olive leaf polyphenols, increased in mycorrhizal plants compared to uninoculated plants by $42 \%$, and its derivatives, oleuroside and ligstroside, increased by $68 \%$ and $48 \%$, respectively. The highest increase was found in the levels of luteolin-7'-O-glucoside (107\% increase), while its sister compound luteolin-4'-O-glucoside increased by $43 \%$. Only verbascoside levels were lower in mycorrhizal plants versus non-mycorrhizal plants declining to below detectable limits. Thus, inoculation of olive saplings with mycorrhizal fungi produces very positive effects on the levels of olive leaf polyphenols. Higher levels polyphenols mean better quality of leaf material for use as herbal medicine.
\end{abstract}

Keywords: ligstroside, luteolin-7'-O-glucoside, oleuropein, rooting of olive cuttings, verbascoside, oleuroside

\section{Introduction}

Olive (Olea europaea) trees are perhaps the original fruit trees that were cultivated (Zohary \& Spiegel, 1975). To many, they are considered holy as these trees have been mentioned in Jewish, Christian and Muslim scriptures (Malik, 2014). However, their present day fame has more to do with the presence of specific health benefitting polyphenols in their fruits and leaves (Soler-Rivas et al., 2000; Tripoli et al., 2005; Uccella, 2001). For example, oleuropein and its derivatives act as antioxidants (Baldioli et al., 1996), and are known to reduce the risks of cancer (Owen et al., 2000; Soler-Rivas et al., 2000; Tripoli et al., 2005) and cardiovascular (Covas, 2007; Manna et al., 2002; Visioli et al., 1998; Wiseman et al., 1996), microbial and even viral diseases (Bisignano et al., 1999; Federici \& Bongi, 1983; Fleming et al., 1973; Lee-Huang et al., 2003). Because of such profound benefits of olive polyphenols, consumption of olive oil and other olive products (including leaf extracts) has been steadily increasing and so is the cultivation of olive on new lands (Connor, 2005; Malik \& Bradford, 2004; Malik, 2011; Sebestiani et al., 2006). It is therefore logical to devise better methods for production or to be able to grow olives in poor or saline soils. Mycorrhizal symbiosis is considered an important method to aid the cultivation of field crops, including olives, even under high salinity or in areas prone to water or nutrient deficiencies (Artursson et al., 2006; Auge, 2004; Dag et al., 2009; Farzaneh et al., 2011; Menge, 1983; Porras-Soriano et al., 2009).

Mycorrhizal fungi form symbiotic associations with most terrestrial plants (Simon et al., 1993; Smith \& Read, 1997). The plant provides photosynthates to the fungi and in turn the hyphae of arbuscular mycorrhizal (AM) fungus extend into the soil and provide water and nutrients, especially the immobile nutrients, to plants (Koide, 1991; Marschner \& Dell, 1994). Therefore, increased tolerance to drought (Allen \& Boosalis, 1983; Auge, 2004; Nelsen \& Safir, 1982; Ruiz-Lozano et al., 1995) and significant improvement in growth and productivity of several plant species have been reported in mycorrhizal plants under water and nutrient deficiencies (Baslam et al., 2011; Citernesi et al., 1998; Estaun et al., 2003; Gerdemann, 1968; Mosse et al., 1975). In addition, protection against pathogens in mycorrhizal plants has also been shown in different cultivars (Castillo et al., 
2006; Espinosa et al., 2014; Liu et al., 2007; Pozo \& Azcon-Aguilar, 2007; Rabie, 1998; Watanarojanaporn et al., 2011). Since polyphenols play an important role in plant resistance to pests (Corcuera, 1993; Feeny, 1976; Jones \& Klocke, 1987; Lattanzio, 2006; Nicholson \& Hammerschmidt, 1992) and are of immense benefit to human health, we started to study the role of mycorrhizae in changing the levels of polyphenols in different plants (Malik et al., 2015a, 2015b). Our initial studies showed that while some polyphenols increased in mycorrhizal plants compared to uninoculated control plants, some other polyphenol species actually decreased (Malik et al., 2015a, 2015b). This study was therefore conducted to investigate whether or not the polyphenols of olive leaves (including the prized polyphenol 'oleuropein') increase in the leaves of mycorrhizal vs non-mycorrhizal olive saplings.

\section{Materials and Methods}

\subsection{Plant Growth and Propagation}

Thirty freshly rooted saplings of olive cultivar 'Arbequina' were gifted to us by Mr. Jim Henry, owner of 'Texas Olive Ranch' Carrizo Springs, TX. Samples of roots taken from several saplings indicated that they had established symbiosis with arbuscular mycorrhizal [AM] fungi and therefore, could not be used directly for this study due to lack of uninoculated controls. Therefore, these saplings were grown for 1 year (so that the these plants become big enough so we could take fresh cuttings from these plants to induce new clean roots) in $22 \times 38$ $\mathrm{cm}$ plastic pots filled with commercial growth media (Premier 'Pro-mix-BX', supplied by Premier Horticulture Inc., Quakertown, PA). The plants were supplied with the commercial nutrient 'Miracle Grow' as per manufacturer's instruction.

Fifteen centimeter long branches from one year old 'Arbequina' olive trees (growing in the greenhouse at USDA-ERRC facility in Wyndmoor, PA) were used to induce rooting. The cuttings were first soaked in sterile water for $2 \mathrm{hrs}$, then immersed for $5 \mathrm{~min}$ in $8.2 \%$ sodium hypochlorite, and then rinsed three times with sterile water. Leaves were removed from the lower $5 \mathrm{~cm}$ portion of the cutting. A fresh oblique cut was made at the bottom of the cutting and the cutting was rolled in hormone powder ('TakeRoot', Garden Safe Brand supplied by Schultz Company, Bridgeton, MO). The hormone-treated portions of the cuttings were gently inserted in $22 \times 25$ $\mathrm{cm}$ plastic pots filled with vermiculite that was soaked with $0.3 \%$ hydrogen peroxide made in sterile water. The cuttings were immediately sprayed with sterile water, and then covered with a large beaker to maintain high humidity. The cuttings were sprayed with water 4 times daily and $500 \mathrm{ml}$ of $0.3 \%$ hydrogen peroxide were added (hydrogen peroxide provides increased oxygen and suppress microbial growth and hence promote rooting) to each pot twice a week. The pots were kept on heating pads to maintain $25^{\circ} \mathrm{C}-27^{\circ} \mathrm{C}$, and were given $10 \mathrm{hrs}$. photoperiod using grow lights. After 7 weeks, the rooted cuttings were divided into two groups; one group was dedicated to be inoculated and other was our uninoculated control

The rooted cuttings were planted in Deepot Cells, $656 \mathrm{ml}$ (Stuewe and Sons, Inc. Corvallis, OR) filled with a mixture of Premier Pro-mix BX and vermiculite (1:1). One group of rooted cuttings was inoculated with 750 spores of Rhizophagus intraradices in $1 \mathrm{ml}$ of distilled water. The inoculated and control plants were grown for 3 months in a Conviron growth chamber, set at $10 \mathrm{hrs}$. photoperiod (daytime temp $25{ }^{\circ} \mathrm{C}$, and night temp $18{ }^{\circ} \mathrm{C}$ ). After 3 months, the plants were transferred to the greenhouse (in the month of Febraury), where temperature ranged between as low as $10^{\circ} \mathrm{C}$ during the night and as high as $27^{\circ} \mathrm{C}$ during the day.

$R$. intraradices fungus were grown in petri dishes on Ri.tDNA carrot roots (St-Arnand et al., 1996).

Nine months after the start of the experiment total number of leaves in each replicate of mycorrhizal and non-mycorrhizal plant were counted and the height of each plant was measured to document differences in plant growth as result of mycorrhizal inoculation.

\subsection{Polyphenol Extraction from the Leaves}

The leaves sampled from inoculated and control olive saplings were immediately frozen and stored at $-80{ }^{\circ} \mathrm{C}$ and were ground in liquid nitrogen for extraction. The polyophenols were extracted from powdered leaf material in $80 \%$ methanol as described previously (Malik et al., 2015).

\subsection{Separation, Quantitation and Identification of Polyphenols in Extracts}

The chromatographic separation of the methanol extract was performed as reported before(Malik et al., 2015) with a Nano-Acquity (Waters, Milford, MA) ultrahigh performance liquid chromatographer (UHPLC) equipped with an Acquity UPLC BEH C18, $1.7 \mu \mathrm{m}(1 \times 100 \mathrm{~mm})$ column (Waters) maintained at $40{ }^{\circ} \mathrm{C}$ and running at $60 \mu \mathrm{l} / \mathrm{minute}$. The UHPLC-UV chromatogram was obtained by attaching to the UHPLC instrument an Acquity TUV detector (Waters) set to scan at $280 \mathrm{~nm}$. The solvent gradient was modified, starting with water-acetonitrile 90:10 (0.1\% formic acid) for 2 minutes and ramped linearly to water-acetonitrile $70: 30(0.1 \%$ formic acid $)$ at a 
final time of 18 minutes, maintained at that solvent composition for 2 minutes and followed with a columns wash of water-acetonitrile 15:85 (0.1\%) formic acid) and returning to the initial condition at 25 minutes. A 10 minutes stabilization time was allowed between injections. Samples for the mycorrhizal and non-mycorrhizal plants were separately combined and mixed with $10 \mu \mathrm{l}$ of a kaempferol solution (internal standard, $5 \mu \mathrm{g} / \mathrm{ml}$ ). Three injections of $4 \mu \mathrm{l}$ were made for each sample for determination of the concentration change according to the peak height determined by MassLynx v.4.1 software (Waters). The same chromatographic conditions were used for the mass spectrometry analysis.

The mass spectrometry analysis was accomplished by connecting the effluent of the UHPLC instrument to a Synapt G1 quadrupole-time of flight mass spectrometer (Waters) operating in the V mode (resolving power of $8,000 \mathrm{FWHM}$ ) and with an electrospray ionization (ESI) probe operated in the positive or negative mode and controlled by MassLynx v.4.1 software (Waters). The instrument parameters were $2.7 \mathrm{kV}$ capillary voltage, $48 \mathrm{~V}$ extractor voltage, $300 \mathrm{~L} / \mathrm{h}$ desolvation gas $\left(\mathrm{N}_{2}\right)$ flow, and $120{ }^{\circ} \mathrm{C}$ and $150{ }^{\circ} \mathrm{C}$ source and desolvation temperatures, respectively. The MS/MS of the deprotonated precursor ions $[\mathrm{M}-\mathrm{H}]^{-}$were obtained by collision-induced dissociation with argon gas at $0.9 \mathrm{ml} / \mathrm{min}$ with the collision energy ramped between 6 to $30 \mathrm{eV}$.

\section{Results and Discussion}

\subsection{Effects of Mycorrhizal Fungi Inoculation on Plant Growth}

Olive saplings inoculated with $R$. intraradices at early rooting stage showed increased plant growth relative to the uninoculated controls (Figure 1).

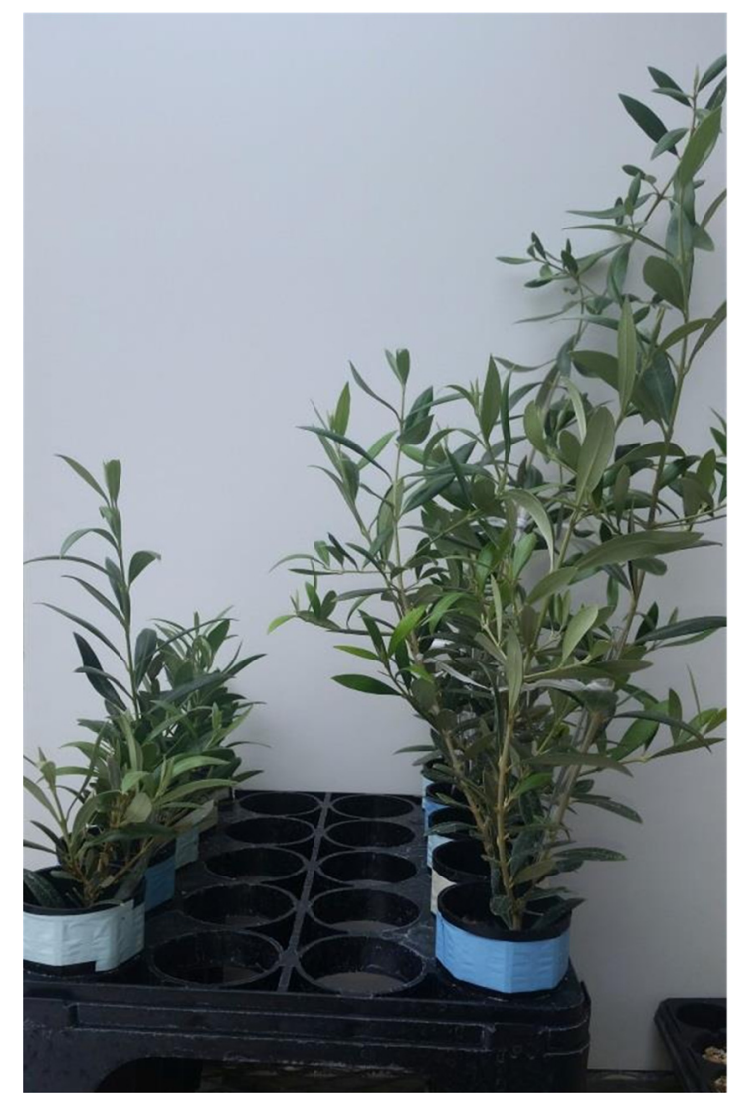

Figure 1. Growth differences in mycorrhizal (inoculated with Rhizophagus intraradices; on the right) and uninoculated (on the left) 'Arbequina' olive saplings nine months after rooting and inoculation

The picture was taken nine months after inoculation. The increase in plant height was $146 \%$ and the number of leaves were $117 \%$ more in mycorrhizal plants compared to uninoculated controls (Table 1). This increased plant growth in mycorrhizal plants is consistent with previous reports that showed increase in growth in different plants, including olives (Artursson et al., 2006; Auge, 2004; Dag et al., 2009; Farzaneh et al., 2011). The new and important findings of this study, however, are changes in polyphenol levels (Table 2). 
Table 1. Differences in plant growth between mycorrhizal and uninoculated plants

\begin{tabular}{llll}
\hline Treatment & Plant Height (centimeters) & Number of Leaves & Root Colonization \\
\hline Non Myc & $19.6 \pm 2.3$ & $50.6 \pm 10.8$ & $0 \%$ \\
Myc & $48.3 \pm 7.6$ & $109 \pm 9.0$ & $80.04 \% \pm 2.3 \%$ \\
Percent increase over Non Myc & $146 \%$ & $117 \%$ & \\
\hline
\end{tabular}

Note. All values are Average \pm SEM.

All Data Significant with a P value of less than 0.006 using $t$ test for the significance.

Myc $=$ Mycorrhizal plant.

Table 2. Percent change in the levels of polyphenol in the leaves of olive saplings in mycorrhizal plants compared to uninoculated control

\begin{tabular}{lllll}
\hline Identification of Polyphenols & Peak number & Retention time & $\begin{array}{l}\text { Percent increase over } \\
\text { unioculated controls }\end{array}$ & $\begin{array}{l}\text { Significantly different } \\
\text { at P value using t test }\end{array}$ \\
\hline Luteolin-7'-O-Glucoside & 1 & 10.02 & $107.25 \%$ & 0.0279 \\
Verbascoside & 2 & 10.27 & $-100 \% *$ & - \\
Luteolin-4'-O-Glucoside & 3 & 11.47 & $42.65 \%$ & 0.0327 \\
Oleuropein & 4 & 13.74 & $42.44 \%$ & $<0.0001$ \\
Oleuroside & 5 & 14.46 & $67.89 \%$ & $<0.0001$ \\
Oleuropien derivative & 6 & 14.97 & $32.02 \%$ & $<0.0001$ \\
Ligstroside & 7 & 16.05 & $48.21 \%$ & 0.0166 \\
\hline
\end{tabular}

Note. ${ }^{*}$ Not detected in mycorrhizal plants.

\subsection{Effects of Mycorrhizal Fungi Inoculation on Changes in Levels of Polyphenols}

Figure 2 shows an HPLC profile identifying various polyphenols in the olive leaf extract, which are similar to our previous reports (Malik \& Bradford, 2006; Selin et al., 2012), but with the addition of a few more compounds due to the use of mass spectrometry.

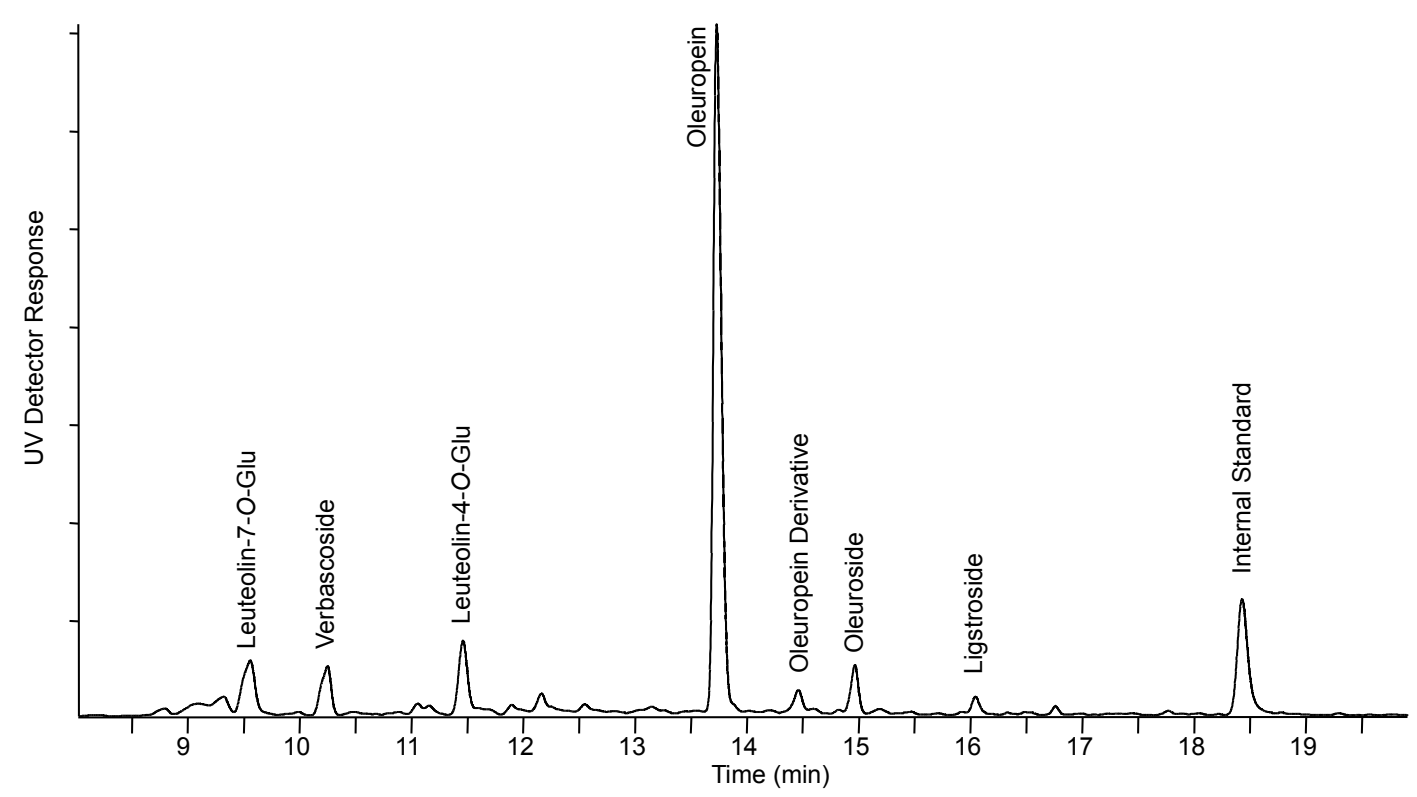

Figure 2. A representative profile of different polyphenols from olive leaf extract separated by HPLC

The identity of the compounds eluting at the corresponding retention time, in Table 2, were determined by using commercially available compounds, comparing retention time and the mass obtained with the mass spectrometer 
for the fallowing entrees: leuteolin-7-O-glucose $([\mathrm{M}-\mathrm{H}]-=447.04$; calculated 447.09, MS/MS fragments at $\mathrm{m} / \mathrm{z}$ 285), verbascoside $([\mathrm{M}-\mathrm{H}]-=621.14$, calculated $621.18, \mathrm{MS} / \mathrm{MS}$ fragments at $\mathrm{m} / \mathrm{z} 461$, and 161), leuteolin-4'-O-glucose $([\mathrm{M}-\mathrm{H}]-=447.04$; calculated 447.09, MS/MS fragments at $\mathrm{m} / \mathrm{z} 285)$, and oleuropein $([\mathrm{M}-\mathrm{H}]-=539.15$; calculated 539.18, MS/MS fragments at $\mathrm{m} / \mathrm{z}$ 377, 307, 275, and 225) (Savarese et al., 2007). The peaks eluting at 14.46 and $14.97 \mathrm{~min}$ have the same mass spectra as oleuropein, with the same fragments at $\mathrm{m} / \mathrm{z}$ 377; 307; 275; and 225 suggesting two isomers of oleuropein. Savarese et al. (2007) reported oleuroside as an isomer eluting after oleuropein, with the same mass spectrum and accordingly, we are assigning the peak at 14.46 as oleuroside based on its longer retention time in the reversed phase column as was reported before (Savarese et al., 2007; Savournin et al., 2001). No further identification was possible for the peak closer to oleuropein at $14.97 \mathrm{~min}$ and is reported as a derivative of oleuropein. The peak eluting at 16.05 was identified as ligstroside, $([\mathrm{M}-\mathrm{H}]-=523.15$; calculated 523.18, MS/MS fragments at $\mathrm{m} / \mathrm{z} 361,291,259$ and 101) as reported before (Savarese et al., 2007).

Although the majority of polyphenols identified in the leaves had increased levels in mycorrhizal plants compared to the uninoculated controls, the level of verbascoside decreased to a point where they were below detection (Table 2). This was the only polyphenol species whose levels decreased in mycorrhizal olive saplings, oleuropein which is a major component of olive leaf polyphenols increased by $42 \%$, and its derivative oleuroside and ligstroside increased by $68 \%$ and $48 \%$, respectively (Table 2 ). The greatest increase was found in the levels of luteolin-7'-O-glucoside (107\% increase), while its sister compound luteolin-4'-O-glucoside increased by $43 \%$ (Table 2). This pattern of increases in certain polyphenol species with decreases in the levels of other polyphenol species, in mycorrhizal plants, compared to controls, has been observed in other plant species (Malik et al., 2015, 2016).

In general, our results show that inoculation of olive sapling's freshly formed roots with mycorrhizal fungi (Rhizophagus intraradices) produces beneficial effects on the growth of the plants and improves the levels of its major polyphenols. Olive polyphenols are well known for several health benefits, described before, and therefore, the current study is important as it provides information regarding improving the quality of commercial olive products.

\section{References}

Allen, M. F., \& Boosalis, M. G. (1983). Effect of two species VA mycorrhizal fungi on drought tolerance of winter wheat. New Phytologist, 93, 67-76. https://doi.org/10.1111/j.1469-8137.1983.tb02693.x

Artursson, V., Finlay, R. D., \& Jansson, J. K. (2006). Interactions between arbuscular mycorrhizal fungi and bacteria and their potential for stimulating plant growth. Environ. Microbiol., 8, 1-10 https://doi.org/ 10.1111/j.1462-2920.2005.00942.x

Auge, M. R. (2004). Arbuscular mycorrhizae and soil/plant water relations. Can. J. Soil Sci., 84, 373-381. https://doi.org/10.4141/S04-002

Baldioli, M., Servili, M., Perretti, G., \& Montedoro, G. F. (1996). Antioxidant activity of tocopherols and phenolic compounds of virgin olive oil. J. Ameri. Oil Chemist Soc., 73, 1589-1593. https://doi.org/10.1007/ BF02523530

Baslam, M., Garmendia, I., \& Goicoechea, N. (2011). Arbascular mycorrhizal fungi (AMF) improved growth and greenhouse-grown lettuce. J. Agric. Food Chem., 59, 10067-10080. https://doi.org/10.1021/jf200501c

Castillo, P., Nico, A. I., Azcón-Aguilar, C., Del Río Rincón, C., Calvet, C., \& Jim Enez Diáz, R. M. (2006). Protection of olive planting stocks against parasitism of root-knot nematodes by arbuscular mycorrhizal fungi. Plant. Path., 55, 705-713. https://doi.org/10.1111/j.1365-3059.2006.01400.x

Connor, D. J. (2005). Adaptation of olive (Olea europaea L.) to water-limited environment. Aust. J. Agric. Res., 56, 1181-1189. https://doi.org/10.1071/AR05169

Corcuera, L. J. (1993). Biochemical basis for resistance of barley to aphids. Phytochem., 33, 741-747. https://doi.org/10.1016/0031-9422(93)85267-U

Covas, M. I. (2007). Olive oil and cardiovascular system. Phar. Res., 55, 175-186. https://doi.org/10.1016/ j.phrs.2007.01.010

Dag, A., Yermiyahu, U., Ben-Gal, A., Zipori, I., \& Kapulnik, Y. (2009). Nursery and post-transplant field response of olive trees to arbuscular mycorrhizal fungi in an arid region. Crop Pasture Sci., 60, 427-433. https://doi.org/10.1071/CP08143 
Espinosa, F., Garrido, I., Ortega, A., Casimiro, I., \& Alverez-Tinaut, M. C. (2014). Redox activities and ROS, $\mathrm{NO}$ and phenylpropanoids production by axenically cultured olive seedling rootsafter interaction with a mycorrhizal or a pathogenic fungus. PLOS ONE, 996, e100132. https://doi.org/10.1371/journal.pone. 0100132

Estaun, V., Camprubi, A., Calvet, C., \& Pinochet, J. (2003). Nursery and field response of olive trees inoculated with two arbuscular mycorrhizal fungi, glomus intraradices and glomus mosseae. J. Amer. Soc. Hort. Sci., $128,767-775$.

Farzaneh, M., Vierheilig, H., Lossl, A., \& Kaul, H. P. (2011). Arbuscular mycorrhizae enhances nutrient uptake in chickpea. Pl. Soil Environ., 57, 465-470.

Feeny, P. P. (1976). Plant apparency and chemical defense. Recent Adv. Phytochem., 10, 1-40. https://doi.org/ 10.1007/978-1-4684-2646-5_1

Gerdemann, J. W. (1968). Vesicular-arbuscular mycorrhiza and plant growth. Annu. Rev. Phytopathol., 6, 397-418. https://doi.org/10.1146/annurev.py.06.090168.002145

Jones, K. C., \& Klocke, J. A. (1987). Aphid feeding deterrency of ellagitannins, their phenolic hydrolysis products and related phenolic derivatives. Entomol. Exp. Appl., 44, 229-234. https://doi.org/10.1111/ j.1570-7458.1987.tb00549.x

Koide, R. T. (1991). Nutrient supply, nutrient demand and plant responses to mycorrhizal infection. New Phytologist, 114, 365-386. https://doi.org/10.1111/j.1469-8137.1991.tb00001.x

Lattanzio, V., Lattanzio, V. L. M., \& Cardinali, A. (2006). Role of phenolics in the resistance mechanism of plants against fungal pathogens and insects. Photochem. Advan. Res., 661, 23-67.

Lee-Huang, S., Zhang, L., Huang, P. L., Chang, Y.-T., \& Huang, P. L. (2003). Anti-HIV activity of olive leaf extract (OLE) and modulation of host cell gene expression by HIV-1infection and OLE treatment. Bio. Bioch. Res. Comm., 307, 1029. https://doi.org/10.1016/S0006-291X(03)01292-0

Liu, J., Maldonado-Mendoza, I., Lopez-Meyer, M., Cheung, F., Town, C. D., \& Harrioson, M. J. (2007). Arbuscular mycorrhizal symbiosis is accompanied by local and systemic alterations in gene expression and an increase in disease resistance in shoot. Plant J., 50, 529-544. https://doi.org/10.1111/j.1365-313X.2007. 03069.x

Malik, N. S. A. (2011). Feasibility of growing olives at selected sites on coastal Texas. J. Agric. Sci. Tech., 5, 139-146.

Malik, N. S. A. (2014). Olive a holy plant with several benefits to human health. Retrieved from http://www.themuslimtimes.org/2014/04/americas/olive-a-holy-plant-with-several-benefits-to-human-health \#ixzz2ysEynTxn

Malik, N. S. A., \& Bradford, J. M. (2004). Genetic diversity and clonal variation among olive cultivars offer hope for selecting cultivars for Texas. J. Am. Pom. Soc., 58, 203-209.

Malik, N. S. A., \& Bradford, J. M. (2006). Changes in oleuropein levels during differentiation and development of floral buds in 'Arbequina' olives. Sci. Hort., 110, 274-278. https://doi.org/10.1016/j.scienta.2006.07.016

Manna, C., D’Angelo, S., Migliardi, V., Loffredi, E., Mazzoni, O., Morrica, P., ... Zappia V. (2002). Protective effect of phenolic fraction from virgin olive oils against oxidative stress in human cells. J. Agric. Food Chem., 50, 6521-6526. https://doi.org/10.1021/jf020565+

Marschner, H., \& Dell, B. (1994). Nutrient uptake in mycorrhiza symbiosis. Pl. Soil, 159, 89-102.

Menge, J. A. (1983). Utilization of vescular-arbuscuar mycorrhizal fungi in agriculture. Can. J. Bot., 61, 1015-1024. https://doi.org/10.1139/b83-109

Mosse, B., Powell, L. I., \& Hayman, D. S. (1976). Plant growth responses to vescular-arbuscuar mycorrhiza. IX. Interactions between VA mycorrhiza, rock phosphate and symbiotic nitrogen fixation. New Phytol., 76, 331-342. https://doi.org/10.1111/j.1469-8137.1976.tb01468.x

Nelsen, C. E., \& Safir, G. R. (1982). Increased drought tolerance of mycorrhizal onion plants caused by improved phosphorus nutrition. Planta, 154, 407-413. https://doi.org/10.1007/BF01267807

Nicholson, R. L., \& Hammerschmidt, R. (1992). Phenolic compounds and their role in disease resistance. Ann. Rev. Phytopath., 30, 369-389. https://doi.org/10.1146/annurev.py.30.090192.002101 
Porras-Soriano, A., Soriano-Martin, M. L., Porras-Piedra, A., \& Azcon, R. (2009). Arbuscular mycorrhiza fungi increased growth, nutrient uptake and tolerance to salinity in olive trees under nursery conditions. $J$. $P l$. Physiol., 166, 1350-1359. https://doi.org/10.1016/j.jplph.2009.02.010

Pozo, M. J., \& Azcon-Aguilar, C. (2007). Unravelling mycorrhiza-induced resistance. Curr. Opin. Pl. Biol., 10, 393-398. https://doi.org/10.1016/j.pbi.2007.05.004

Rabie, G. H. (1998). Induction of fungal disease resistance in vicia faba by dual inoculation with Rhizobium leguminosarum and vesicular-arbascular mycorrhizal fungi. Mycopathology, 141, 159-166. https://doi.org/10.1023/A:1006937821777

Ruiz-Lozano, J. M., Azcon, R., \& Gomez, M. (1995). Effects of arbuscular-mycorrhizal glomus species on drought tolerance: Physiological and nutritional responses. Appl. Envirn. Microb., 61, 456-460.

Savarese, M., De Marco, E., \& Sacchi R. (2007). Characterization of phenolic extracts from olive (Olea europea cv. Pisciottana) by electrospray ionization mass spectrometry. Food Chem., 105, 761-770. https://doi.org/10.1016/j.foodchem.2007.01.037

Savournin, C., Baghdikian, B., Elias, R., Dargouth-Kesraoui, F., Boukef, K., \& Balansard, G. (2001). Rapid high-performance liquid chromatography analysis for the quantitative determination of oleuropein in Olea europaea leaves. J. Agric. Food Chem., 49, 618-621. https://doi.org/10.1021/jf000596+

Sebastiani, L., d'Andria R, Motisi, A., \& Caruso, T. (2006). The olive industry outside the mediterranean. In T. Caruso, A. Motisi, \& L. Sebastiani (Eds.), Proceedings of the 2nd International Seminar, Olivebioteq-Recent Advances in Olive Industry, Marsala, Italy (pp. 183-195). Dipartimento Colture Arboree, Universita di Palermo: Palermo, Italy.

Selin, S., Malik, N. S. A., Perez, J. L., \& Brockington, J. E. (2012). Seasonal changes of individual phenolic compounds in leaves of twenty olive cultivars grown in Texas. J. Agric. Sci. Tech. B, 2, 242-247.

Simon, L., Bousquet, J., Levesque, R. C., \& Lalonde, M. (1993). Origin and diversification of endomycorrhizal fungi and coincidence with vascular plants. Nature, 363, 67-69. https://doi.org/10.1038/363067a0

Smith, S. E., \& Read, D. J. (1997). Mycorrhizal Symbiosis (2nd ed.). Academic Press, San Diego, Calif.

Soler-Rivas, C., Espin, J. C., \& Wichers, H. J. (2000). Oleuropein and related compounds. J. Sci. Food. Agric., 80, 1013-1023. https://doi.org/10.1002/(SICI)1097-0010(20000515)80:7\%3C1013::AID-JSFA571\%3E3.0. $\mathrm{CO} ; 2-\mathrm{C}$

St-Arnaud, M. C., Hamel, C., Vimard, B., Caron, M., \& Fortin, J. A. (1996). Enhanced hyphal growth and spore production of the arbuscular mycorrhizal fungus Glomus intraradices in an in vitro system in the absence of host roots. Myco. Res., 100, 328-332. https://doi.org/10.1016/S0953-7562(96)80164-X

Tripoli, E., Giammanco, M., Tabacchi, G., Di Majo, D., Giammanco, S., \& La Guardia, M. (2005). The phenolic compounds of olive oil: Structure, biological activity and beneficial effects on human health. Nutri. Res. Rev., 18, 98-112. https://doi.org/10.1079/NRR200495

Uccella, N. (2001). Olive biophenols: Biomolecular characterization, distribution and phytolexin histochemical localization in the drupes. Trends Food Sci. Tech., 11, 315-327. https://doi.org/10.1016/S0924-2244(01) 00029-2

Visioli, F., Bellosta, S., \& Galli, C. (1998). Oleuropein, the bitter principle of olives, enhances nitric oxide production by mouse macrophages. Life Sci., 62, 541-546. https://doi.org/10.1016/S0024-3205(97)01150-8

Watanarojanaporn, N., Boonkerd, N., Wongkaew, S., Prommanop, P., \& Teaumroong, N. (2011). Selection of arbuscular mycorrhizal fungi for citrus growth promotion and Phytophthora suppression. Sci Hort, 128, 423-433. https://doi.org/10.1016/j.scienta.2011.02.007

Zohary, D., \& Spiegle-Roy, P. (1975). Beinning of fruit growing in old world. Science, 187, $319-327$. https://doi.org/10.1126/science.187.4174.319

\section{Copyrights}

Copyright for this article is retained by the author(s), with first publication rights granted to the journal.

This is an open-access article distributed under the terms and conditions of the Creative Commons Attribution license (http://creativecommons.org/licenses/by/4.0/). 